\title{
Previsão da longevidade de sementes de faveiro (Dimorphandra mollis Benth.) ${ }^{1}$
}

\author{
MARIA MADALENA F. CHAVES ${ }^{2}$ e ROBERTO USBERTI ${ }^{3,4}$
}

(recebido: 27 de março de 2002; aceito: 9 de outubro de 2003)

\begin{abstract}
Prediction of Dimorphandra mollis Benth. ("faveiro") seed longevity). For the preservation of Brazilian forest resources it becomes necessary the establishment of methodologies to assure the survival and reduction of vulnerability to the extinction of threatened species. The main aim of this work was to study the controlled storage of seeds of "faveiro" (Dimorphandra mollis Benth.), an endangered Brazilian "Cerrado" tree species, in order to determine its viability equation constants allowing for the conservation of those materials as well as to guarantee its availability. Seed moisture contents fresh weight basis were adjusted from the initial values through rehydration above water in a closed container or by drying in desiccator with silica gel, until achieving the desired moisture content values. Seed subsamples of eight moisture contents $(1.6 \% ; 5.2 \% ; 6.9 \% ; 8.4 \% ; 9.2 \% ; 10.6 \% ; 11.4 \%$ and $13.2 \%$, initial value of $9.2 \%)$ were sealed in laminated aluminium-foil packets and stored at 40,50 and $65{ }^{\circ} \mathrm{C}$, until complete survival curves were obtained. Statistical analysis was performed by GLIM software. The species showed orthodox behaviour during storage. An inverse relationship was observed between moisture content and seed longevity. The calculated viability constants to predict $D$. mollis seed longevity are $K_{E}=6.282 ; C_{W}=3.838$; $C_{H}=0.05405 ; \mathrm{C}_{Q}=0.001316$.
\end{abstract}

Key words - Dimorphandra mollis, forest species, hermetic storage, viability equation

RESUMO - (Previsão da longevidade de sementes de faveiro (Dimorphandra mollis Benth.)). A necessidade da preservação dos recursos florestais brasileiros torna necessário o estabelecimento de novas metodologias para assegurar a sobrevivência e a redução da vulnerabilidade à extinção de espécies. O objetivo deste trabalho foi estudar o armazenamento controlado de sementes de faveiro (Dimorphandra mollis Benth.), espécie arbórea típica de Cerrado, visando determinar as constantes da equação de longevidade e, deste modo, permitir a sua conservação e garantir a sua disponibilidade. Os graus de umidade base úmida foram ajustados, a partir do seu valor inicial, através de umidificação sobre água ou, então, em dessecadores com sílica gel, até a obtenção dos valores desejados. Subamostras de sementes com oito graus de umidade $(1,6 \% ; 5,2 \% ; 6,9 \% ; 8,4 \%$; $9,2 \% ; 10,6 \% ; 11,4 \%$ e $13,2 \%$, valor inicial de $9,2 \%$ ) foram acondicionadas, hermeticamente, em embalagens de alumínio e armazenadas a 40,50 e $65^{\circ} \mathrm{C}$, até a obtenção de curvas completas de sobrevivência. As análises estatísticas foram realizadas pelo programa "GLIM". A espécie apresentou comportamento ortodoxo em relação ao armazenamento. Foi observada uma relação inversa entre o grau de umidade e a longevidade das sementes. As constantes obtidas para prever a longevidade de sementes de D. mollis são: $K_{E}=6,282 ; C_{W}=3,838 ; C_{H}=0,05405 ; C_{Q}=0,001316$.

Palavras-chave - armazenamento hermético, Dimorphandra mollis, equação de viabilidade, espécie florestal

\section{Introdução}

O Brasil possui a flora arbórea mais diversificada do mundo, no entanto, a falta de diretrizes técnicas e de conscientização ecológica na sua exploração tem acarretado prejuízos ambientais irreparáveis. Os remanescentes florestais, com raras exceções, encontram-se perturbados e empobrecidos, tornando-se

\footnotetext{
1. Parte da tese de Doutorado, Faculdade de Engenharia Agrícola, Unicamp.

2. Universidade Estadual de Campinas, Faculdade de Engenharia Agrícola, Caixa Postal 6011, 13083-970 Campinas, SP, Brasil

3. Agência de Defesa Agropecuária, ADAESP/SAA, Caixa Postal 960, 13073-001 Campinas, SP, Brasil.

4. Autor para correspondência: usberti@cati.sp.gov.br
}

um recurso cada vez mais escasso e em alarmante processo de empobrecimento genético, agravado principalmente pela falta de técnicas silviculturais apropriadas ao manejo sustentado das florestas nativas remanescentes.

A manutenção de um banco de germoplasma "ex-situ" de espécies florestais seria relevante para o conhecimento e manutenção desses materiais. Entretanto, não se dispõe, no momento, de tecnologia apropriada para a sua implantação, principalmente pelo desconhecimento do potencial de armazenamento dessas espécies. Esta tem sido meta constante entre os pesquisadores, tecnologistas e produtores de sementes para subsidiar o manejo racional dessas sementes, visando vários objetivos, desde a manutenção de bancos de germoplasma até a comercialização e estabelecimento de uma nova cultura (Usberti \& Gomes 1998). 
As sementes de espécies de zonas tropicais e temperadas seguem basicamente três padrões de comportamento durante o armazenamento: ortodoxo, intermediário e recalcitrante. As sementes ortodoxas são tolerantes à dessecação e à temperaturas baixas, 0 que permite a retenção da germinação por longos períodos de armazenamento. As sementes recalcitrantes são sensíveis à desidratação, mesmo em grau de umidade ainda elevado; embora mantidas embebidas, tais sementes perdem a viabilidade em um período de tempo relativamente curto. Há ainda sementes que sofrem danos durante a secagem $( \pm 10 \%$ de umidade $)$ e também pelo frio, não se comportando inteiramente como ortodoxas ou recalcitrantes, sendo classificadas como intermediárias (Hong \& Ellis 1996).

Assim, a previsão da longevidade de sementes ortodoxas seria de extrema valia para os objetivos propostos e, para tanto, a equação de viabilidade proposta por Ellis \& Roberts (1980) e apresentada a seguir, tem se mostrado altamente confiável para as espécies já estudadas, com níveis de correlação excelentes entre os valores observados em várias pesquisas e os valores calculados:

$$
\begin{aligned}
\mathrm{v}= & K_{i}-\mathrm{p} / 10 K_{E}-C_{W} \log \mathrm{m}-C_{H^{\mathrm{t}}}-C_{Q^{\mathrm{t}^{2}}}, \text { onde: } \\
\mathrm{v}= & \text { porcentagem de viabilidade prevista; } \\
\mathrm{p}= & \text { período de tempo em dias; } \\
\mathrm{m}= & \text { grau de umidade das sementes }(\%, \text { base } \\
& \text { úmida); } \\
\mathrm{t}= & \text { temperatura de armazenamento }\left({ }^{\circ} \mathrm{C}\right) ; \\
K_{i}= & \text { constante que quantifica a qualidade inicial } \\
& \text { de cada lote de sementes antes do } \\
& \text { armazenamento; } \\
K_{E}= & \text { constante para cada espécie; } \\
C_{W}= & \text { indica a resposta logarítmica da longevidade } \\
& \text { das sementes para o grau de umidade; } \\
C_{H}, & C_{Q}=\text { constantes linear e quadrática do termo } \\
& \text { temperatura, respectivamente, descrevendo } \\
& \text { o efeito da temperatura de armazenamento } \\
& \text { na longevidade das sementes. }
\end{aligned}
$$

A constante $K\left(K=K_{E}-C_{H} \mathrm{t}-C_{Q} \mathrm{t}^{2}\right)$ fornece uma média simplificada da equação de viabilidade quando somente uma temperatura é considerada (Ellis et al. 1986). Desde que os valores das constantes desta equação são específicos para cada espécie vegetal, torna-se necessária sua determinação para cada essência florestal de interesse econômico, ecológico e científico. Essa equação permite prever, de maneira simples e acurada, a porcentagem de viabilidade esperada para qualquer lote de sementes durante o armazenamento em diferentes valores de temperatura e grau de umidade.
A equação baseia-se em quatro características essenciais da fisiologia de sementes (Ellis et al. 1982), a saber: a) embora a sobrevivência de lotes de sementes ou cultivares possa ser diferente quando armazenados sob condições idênticas, as curvas de sobrevivência são sigmóides simétricas, podendo ser descritas pela distribuição normal negativa cumulativa que, em determinadas espécies, tem o mesmo desvio padrão em qualquer combinação de temperatura e grau de umidade; b) a diferença relativa entre os lotes de sementes é mantida em todas as condições ambientais de armazenamento, em função do efeito relativo sobre a longevidade, pois qualquer alteração na temperatura ou grau de umidade é a mesma para todos os lotes; c) existe uma relação logarítmica negativa entre a longevidade e o grau de umidade das sementes; d) a longevidade da semente aumenta ligeiramente menos que exponencialmente com o decréscimo na temperatura, de tal modo que o $\mathrm{Q}_{10}$ (coeficiente de temperatura para mudança na taxa de perda de viabilidade para cada $10{ }^{\circ} \mathrm{C}$ de aumento na temperatura) aumenta com a temperatura.

Com a expansão da fronteira agrícola nas regiões de cerrado, muitas espécies arbóreas encontram-se ameaçadas de extinção, entre elas, o faveiro (Dimorphandra mollis Benth.), uma espécie nativa do Brasil, pertencente à família Caesalpiniaceae, encontrada em regiões de cerrado nos estados do Pará, Goiás, Mato Grosso, Minas Gerais, São Paulo e Mato Grosso do Sul (Silva 1986), com grande importância principalmente para a indústria farmacêutica, na produção de princípios ativos constituídos por compostos fenólicos, tanino e rutina. $\mathrm{O}$ fruto do faveiro é importante fonte de rutina, na proporção de $8 \mathrm{~g}$ para $100 \mathrm{~g}$ de pericarpo. A rutina tem importância terapêutica em virtude de determinar a normalização da resistência e permeabilidade das paredes dos vasos capilares (Tomassini \& Mors 1966).

Desta forma surge a preocupação em se estabelecer procedimentos para a conservação desta espécie. O armazenamento adequado permite a conservação dos recursos genéticos das populações naturais através de sementes. No entanto, a preservação da viabilidade depende do conhecimento do comportamento das sementes em relação às condições de armazenamento a que são submetidas.

O presente trabalho teve como objetivo estudar o armazenamento controlado de sementes de D. mollis, para se determinar as constantes da equação de longevidade e, deste modo, permitir sua conservação bem como garantir sua disponibilidade. 


\section{Material e métodos}

O estudo foi realizado em dois locais, no Laboratório Central de Sementes do Departamento de Sementes, Mudas e Matrizes da Cati (Coordenadoria de Assistência Técnica Integral) e no Laboratório de Tecnologia Pós-Colheita da Faculdade de Engenharia Agrícola, Unicamp, Campinas, SP, no período de agosto de 1998 a setembro de 2001.

Colheita das sementes - Os frutos de Dimorphandra mollis Benth. foram colhidos de 100 árvores ao longo da rodovia Aguai-Pirassununga (40 km), Estado de São Paulo, num total de 219 árvores (povoamentos diferentes), no período de agosto a setembro de 1998, nas coordenadas geográficas de $21^{\circ} 59^{\prime} 52^{\prime \prime} \mathrm{S}$ e $47^{\circ} 25^{\prime} 28^{\prime \prime} \mathrm{W}$, a uma altitude de $620 \mathrm{~m}$. A precipitação média anual é de $1.314 \mathrm{~mm}$, apresentando temperatura média anual de $19,8{ }^{\circ} \mathrm{C}$ e um clima tropical de altitude.

Após a colheita, os frutos que apresentavam uma pequena fenda lateral ou totalmente fechados, foram espalhados sobre lonas em camadas finas, lá permanecendo durante dois dias para facilitar a extração manual das sementes. A espécie apresentou de cinco a 18 sementes por fruto e 4.786 sementes $/ \mathrm{kg}$.

$\mathrm{O}$ beneficiamento empregado para essa espécie foi o manual, retirando-se as sementes chochas, verdes, quebradas e pedaços de frutos, de maneira a melhorar a pureza física e a qualidade do lote das sementes. Após o beneficiamento, as sementes foram colocadas em embalagem de polietileno (194 $\mu \mathrm{m}$ de espessura, com permeabilidade ao vapor de água de $1,9 \mathrm{~g}$ água $/ \mathrm{m}^{2}$ ) e armazenadas durante 10 dias em câmara fria a $5{ }^{\circ} \mathrm{C}$ para homogeneização do grau de umidade entre e dentro das sementes.

Determinação do grau de umidade das sementes - O grau de umidade das sementes (base úmida) foi determinado com três subamostras de $5 \mathrm{~g}$ de sementes inteiras, em estufa de circulação forçada, a $105 \pm 3{ }^{\circ} \mathrm{C}$ durante 24 horas (Brasil 1992) e pesadas em balança analítica com sensibilidade de $0,0001 \mathrm{~g}$. Acondicionamento e armazenamento das sementes - Os graus de umidade das sementes foram ajustados a $25^{\circ} \mathrm{C}$ a partir de seu valor inicial $(9,2 \%)$, antes do armazenamento, por meio de umidificação em bandejas de náilon colocadas em uma caixa de polietileno, $3 \mathrm{~cm}$ acima de uma lâmina de água ou por secagem em dessecadores com sílica gel, constantemente regenerada, até a obtenção dos valores de umidade desejados (tabela 1).

Todas essas operações foram delineadas de modo a evitar uma possível injúria às sementes, causada por uma secagem/umidificação rápida. As sementes foram então colocadas em embalagem de polietileno (194 $\mu \mathrm{m}$ de espessura, com permeabilidade ao vapor de água de $1,9 \mathrm{~g}$ água $/ \mathrm{m}^{2}$ ) e após um período de cinco dias em câmara fria a $5{ }^{\circ} \mathrm{C}$, para homogeneização do grau de umidade entre e dentro das sementes, o grau de umidade foi determinado.

Durante os processos de secagem e reidratação das sementes, as subamostras foram pesadas periodicamente, para controle da quantidade de água removida ou adquirida,
Tabela 1. Períodos de umidificação e secagem (dias) a $25^{\circ} \mathrm{C}$, necessários para atingir os níveis desejados de umidade (\%, base úmida), para $D$. mollis a partir do valor inicial de grau de umidade.

Table 1. Dehydration and rehydration period (days) at $25^{\circ} \mathrm{C}$, required to achieve desired seed mc values (\%, fresh weight basis) for Dimorphandra mollis, from initial mc value.

\begin{tabular}{|c|c|}
\hline Período necessário (dias) & Grau de umidade (\%) \\
\hline \multicolumn{2}{|c|}{ Secagem } \\
\hline 0 & 9,2 \\
\hline 1 & 8,4 \\
\hline 2 & 6,9 \\
\hline 10,4 & 5,2 \\
\hline 168 & 1,6 \\
\hline \multicolumn{2}{|c|}{ Reidratação } \\
\hline 0 & 9,2 \\
\hline 2,0 & 10,6 \\
\hline 5,0 & 11,4 \\
\hline 12,0 & 13,2 \\
\hline
\end{tabular}

conforme metodologia adotada por Valentini (1992).

As sementes foram acondicionadas em embalagens de alumínio hermeticamente fechadas em termossoldadora marca Sentinel, modelo 1212 ASD, operando com uma barra aquecida a $204^{\circ} \mathrm{Ce} 2$ " de contato. O papel laminado apresenta estrutura poliester (PET)/alumínio(Al)/polietileno de baixa densidade (PEBD), com espessura total de $120 \mu \mathrm{m}$, por componentes 12/15/90 $\mu \mathrm{m}$ (PET/Al/PEBD).

A seguir, as embalagens foram armazenadas a $40,50 \mathrm{e}$ $65^{\circ} \mathrm{C}$ em estufas FANEM, com controladores eletrônicos de temperatura marca ELETROLAB $\left( \pm 0,5^{\circ} \mathrm{C}\right)$, até a obtenção de curvas completas de deterioração, conforme metodologia de Ellis \& Roberts (1980). A tabela 2 mostra os graus de umidade de sementes de $D$. mollis analisados durante o armazenamento. Observa-se que não foram incluídos os valores de graus de umidade abaixo de $9,2 \%$ a $40{ }^{\circ} \mathrm{C}$, pois demandaria um longo tempo para a obtenção da curva de sobrevivência; além disso, os valores de graus de umidade para $50{ }^{\circ} \mathrm{C}$ e $65^{\circ} \mathrm{C}$ não foram exatamente iguais devido à quantidade limitada de sementes.

Germinação das sementes - $\mathrm{O}$ teste de germinação foi realizado em rolo de papel do tipo "germitest", com quatro subamostras de 50 sementes, a $25^{\circ} \mathrm{C}$ e luz contínua. As contagens foram realizadas após 7 e 10 dias após a semeadura, considerando-se como germinadas as sementes que emitiram a raiz primária, conforme critério adotado por Dickie \& Smith (1995). Botanicamente, a germinação é considerada como a retomada de crescimento do embrião, com a conseqüente ruptura do tegumento pela raiz primária (Labouriau 1983).

As sementes de faveiro foram escarificadas manualmente com lixa e posteriormente tratadas a seco com Thiram $70 \%$ 
Tabela 2. Graus de umidade de sementes de Dimorphandra mollis analisados durante armazenamento a $40{ }^{\circ} \mathrm{C}, 50{ }^{\circ} \mathrm{C}$ e $65^{\circ} \mathrm{C}$.

Table 2. Dimorphandra mollis seed moisture content values analysed during storage at $40{ }^{\circ} \mathrm{C}, 50^{\circ} \mathrm{C}$ and $65^{\circ} \mathrm{C}$.

\begin{tabular}{cccccccc}
\hline $\begin{array}{c}\text { Temperatura de } \\
\text { Armazenamento }\left({ }^{\circ} \mathrm{C}\right)\end{array}$ & \multicolumn{6}{c}{$\begin{array}{c}\text { Graus de umidade obtidos } \\
(\%)\end{array}$} \\
\hline $40^{\circ} \mathrm{C}$ & 13,2 & 11,4 & 10,6 & 9,2 & & \\
$50^{\circ} \mathrm{C}$ & 13,2 & 11,4 & 10,6 & 9,2 & 6,9 & \\
$65^{\circ} \mathrm{C}$ & 13,2 & 11,4 & 10,6 & 9,2 & 8,4 & 5,2 & 1,6 \\
\hline
\end{tabular}

(3 g. $\mathrm{kg}^{-1}$ de sementes) antes da instalação do teste de germinação, pois em testes preliminares foi constatada uma grande incidência de fungos nas subamostras.

Para todas as sementes com grau de umidade inferior a $6 \%$, foi realizada uma reidratação lenta, previamente ao tratamento com fungicida e à instalação do teste de germinação, para evitar possíveis danos provocados pela embebição rápida (Ellis et al. 1988). As sementes foram mantidas por 48 horas a $25{ }^{\circ} \mathrm{C}$, em bandejas de náilon e colocadas sobre um apoio no interior de uma caixa de polietileno vedada a, aproximadamente, $3 \mathrm{~cm}$ de uma lâmina de água destilada.

Procedimento estatístico - Para cada combinação de grau de umidade/temperatura de armazenamento foi determinada a curva de sobrevivência, com os valores de porcentagem de germinação. Na obtenção da equação de viabilidade, torna-se necessária a transformação dos valores de porcentagem de germinação em probit, pois deste modo os ciclos de vida individuais das sementes ficam uniformemente distribuídos (Ellis \& Roberts 1980).

A origem das retas no eixo Y nunca convergem para o mesmo ponto, necessitando de um ajuste estatístico em cada curva de sobrevivência, forçando as retas a atingirem o mesmo valor com o menor erro possível (constante $K i$ ). Para tanto foi utilizado o programa estatístico GLIM (Baker \& Nelder 1978), com a obtenção dos respectivos valores de sigma que, em termos práticos, indica o tempo necessário para a redução da viabilidade das sementes de um probit, como por exemplo, de probit 1 para probit zero $(84,1 \%$ e $50 \%$ de germinação, respectivamente).

Para melhor compreensão, os dados de porcentagem de germinação, depois de armazenamento a cada combinação de grau de umidade/temperatura, foram colocados em gráficos $\mathrm{X}-\mathrm{Y}$ e as linhas de regressão linear foram obtidas a partir de valores de probit, através da mudança da escala no eixo $\mathrm{Y}$.

Com o uso de logaritmos decimais de sigma e de grau de umidade, para cada tratamento umidade/temperatura, foi possível a obtenção das constantes específicas para a definição da equação de longevidade para a espécie.

\section{Resultados e Discussão}

Secagem das sementes - A secagem das sementes de D. mollis, a partir do valor inicial de $9,2 \%$ até a obtenção do grau de umidade mais baixo $(1,6 \%)$, foi alcançada após 168 dias de armazenamento em sílica gel (figura 1), indicando uma relação inversa entre o grau de umidade e o período de secagem e, também, uma redução na velocidade do processo. Hall (1980) afirmou que esta velocidade decrescente é devida à taxa de transporte interno da água ser menor do que a taxa de evaporação.

De acordo com Vertucci \& Leopold (1987), existem três tipos de água ligada que ocorrem nos tecidos: em graus de umidade muito baixos, a água nas sementes é retida por ligações muito fortes, enquanto que em graus de umidade intermediários e altos é mantida por ligações fracas e água multimolecular, respectivamente.

Esses resultados estão de acordo com os obtidos por Ellis et al. (1988) para três espécies, mostrando que reduções do grau de umidade até estes níveis não acarretam danos às sementes. Como se observa na tabela 3, a secagem das sementes de faveiro em sílica gel não alterou a sua qualidade fisiológica, pois as porcentagens de germinação foram semelhantes para

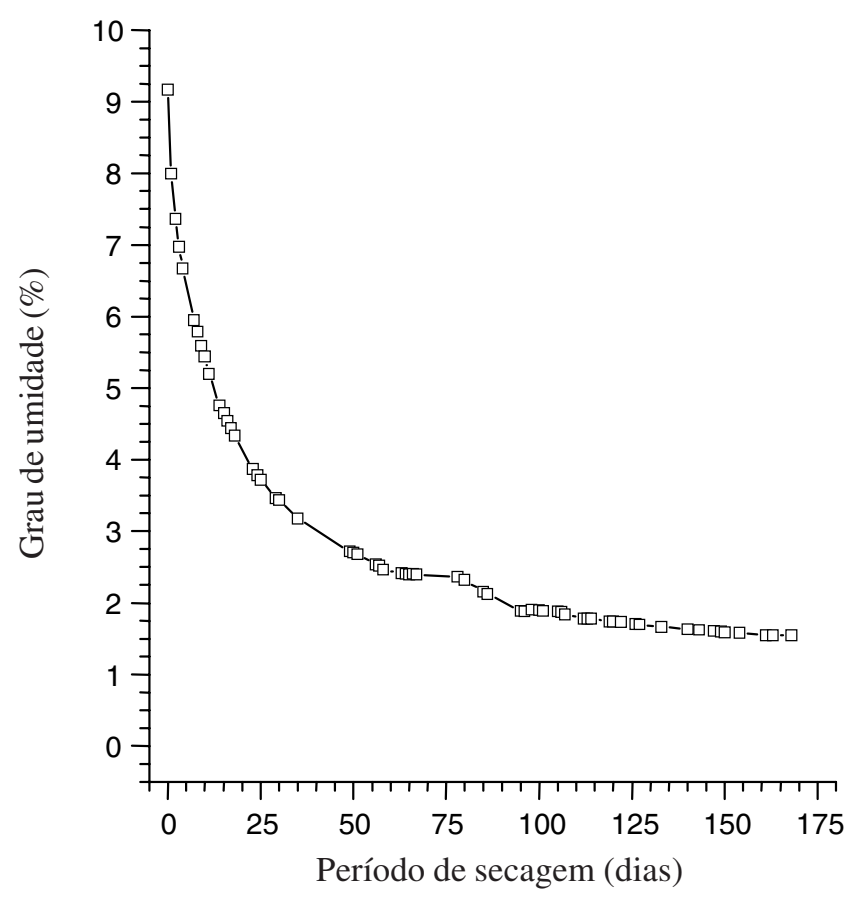

Figura 1. Curva de secagem de sementes de Dimorphandra mollis sobre sílica gel a $25^{\circ} \mathrm{C}$.

Figure 1. Dimorphandra mollis seed drying rate over silica gel at $25^{\circ} \mathrm{C}$. 
Tabela 3. Médias de germinação (\%) de sementes em diferentes graus de umidade (\%, base úmida) de D. mollis, após secagem em sílica gel. C.V. = Coeficiente de variação. Médias seguidas da mesma letra não diferem estatisticamente entre si pelo teste de Tukey $(p<0,05)$.

Table 3. Seed germination values (\%) for Dimorphandra mollis with several mc (\%, fresh weight basis), after drying period over silica gel. C.V. variation coefficient. Means followed by the same letter are not statisfically different by means of Tukey test $(p<0,05)$.

\begin{tabular}{cccc}
\hline Grau de umidade & $\begin{array}{c}\text { Germinação } \\
(\%)\end{array}$ & $\begin{array}{c}\text { C.V. } \\
(\%)\end{array}$ & $\begin{array}{c}\text { Probit } \\
(\%)\end{array}$ \\
\hline 1,6 & $84,5 \mathrm{a}$ & 3,5 & 1,016 \\
5,2 & $86,0 \mathrm{a}$ & 3,5 & 1,081 \\
6,9 & $85,3 \mathrm{a}$ & 3,5 & 1,050 \\
8,4 & $84,5 \mathrm{a}$ & 0,9 & 1,016 \\
$9,2^{*}$ & $86,5 \mathrm{a}$ & 0,7 & 1,103 \\
\hline
\end{tabular}

* Grau de umidade inicial

todas as subamostras controle. Xiarong et al. (1998), comparando a eficiência da secagem de sementes em sílica gel e freezer, em termos da taxa de secagem, perda do grau de umidade, custo relativo e morte das sementes, constataram que os dois procedimentos foram semelhantes; no entanto, em sílica gel foram registrados menores graus de umidade e os custos foram mais baixos.

A secagem das sementes proporciona redução no metabolismo e conseqüente estado de quiescência do embrião. As sementes, neste estado, resistem às condições adversas do ambiente e, quando expostas à condições adequadas e na ausência de dormência, têm a capacidade de retomada do metabolismo no processo de germinação (Bewley \& Black 1994).

Houve efeito significativo $(p<0,01)$ da interação grau de umidade/temperatura e período de armazenamento. Entretanto, as combinações grau de umidade/temperatura no armazenamento não afetaram significativamente o valor de $K_{i}$ (qualidade inicial das sementes), o que é esperado ocorrer em sementes ortodoxas. Para a realização da análise estatística, considerou-se a combinação entre grau de umidade e temperatura de armazenamento como um tratamento, totalizando 16 tratamentos para as temperaturas 40,50 e $65^{\circ} \mathrm{C}$. O valor de $K_{i}$ calculado para D. mollis $(0,999)$ eqüivale a $84,1 \%$ de germinação.

Curvas de sobrevivência - As curvas de sobrevivência de sementes de Dimorphandra mollis a 40, 50 a $65^{\circ} \mathrm{C}$ são apresentadas nas figuras 2,3 e 4, respectivamente, mostrando os efeitos do grau de umidade e da temperatura no potencial de armazenamento das sementes.

Os resultados revelam distribuição normal na longevidade das sementes e, consequentemente, as curvas de sobrevivência obtidas foram sigmoidais cumulativas negativas. As porcentagens de germinação foram transformadas em probit e plotadas linearmente em relação ao período de armazenamento das sementes. Ellis (1984) demonstrou que as curvas de sobrevivência das sementes apresentaram o mesmo formato, diferindo entre si apenas em relação ao período de deterioração controlada, mas apresentando todas um mesmo desvio padrão e, consequentemente, diferentes viabilidades médias.

Nas figuras 2, 3 e 4 observa-se que, independentemente da temperatura de armazenamento, o aumento da umidade das sementes acarretou redução

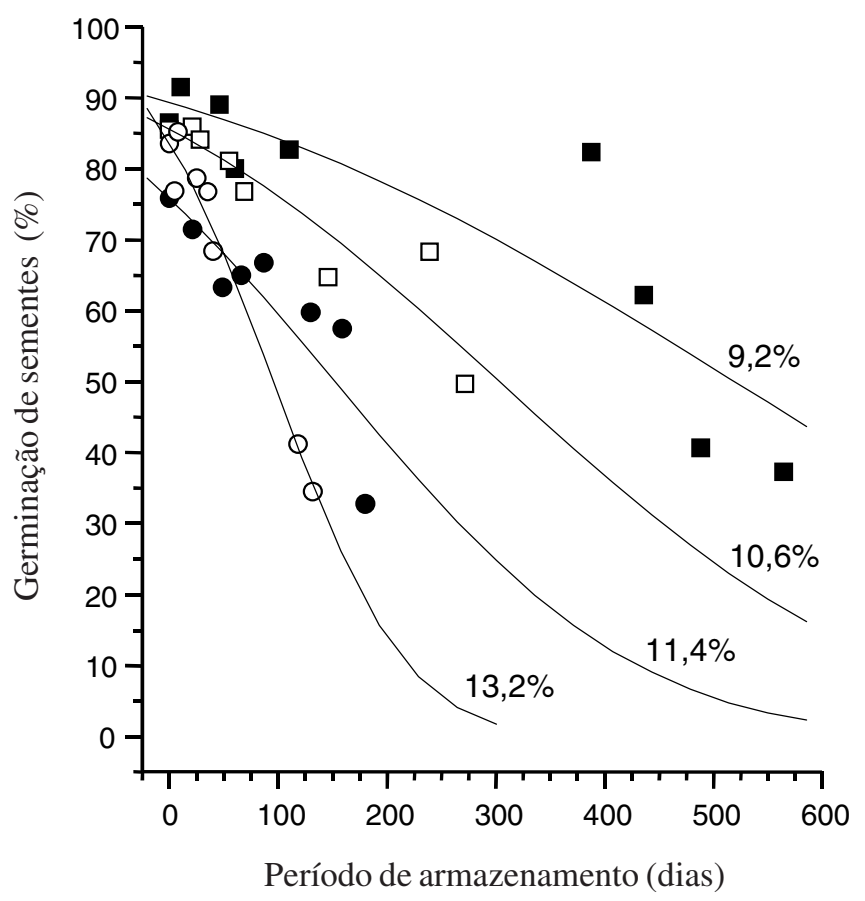

Figura 2. Curvas de sobrevivência de sementes de Dimorphandra mollis, armazenadas a $40{ }^{\circ} \mathrm{C}$ com graus de

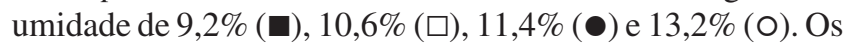
símbolos e as linhas sólidas representam porcentagens de germinação e curvas de sobrevivência em probit, respectivamente.

Figure 2. Probit seed survival curves at $40{ }^{\circ} \mathrm{C}$ for Dimorphandra mollis with $9.2 \%(\square), 10.6 \%(\square), 11.4 \%$ (•) and $13.2 \%$ (O) moisture content. Symbols and solid lines represent germination percentages and probit survival curves, respectively. 
de sua longevidade, mais pronunciada nas umidades mais elevadas $(11,4 \%$ e $13,2 \%)$, em associação com as temperaturas mais altas. Verifica-se, também, que o aumento do grau de umidade aumentou a inclinação das curvas em relação à ordenada, ficando deste modo evidenciado o efeito acentuado deste parâmetro na longevidade dessas sementes.

Para as sementes com grau de umidade de $9,2 \%$ e armazenadas a $40^{\circ} \mathrm{C}$ foram necessários 527,7 dias para a germinação decrescer de um probit, como por exemplo, de probit 0 para probit -1 (50\% e $15,5 \%$, respectivamente); entretanto, quando armazenadas a $65^{\circ} \mathrm{C}$ esse valor reduziu-se para apenas 2,72 dias (figuras 2, 4).

A análise dos efeitos de grau de umidade e de temperatura na longevidade das sementes tem sido preocupação constante de vários pesquisadores, como Ellis et al. (1990), que detectaram resposta significativa para o efeito da umidade na longevidade de sementes

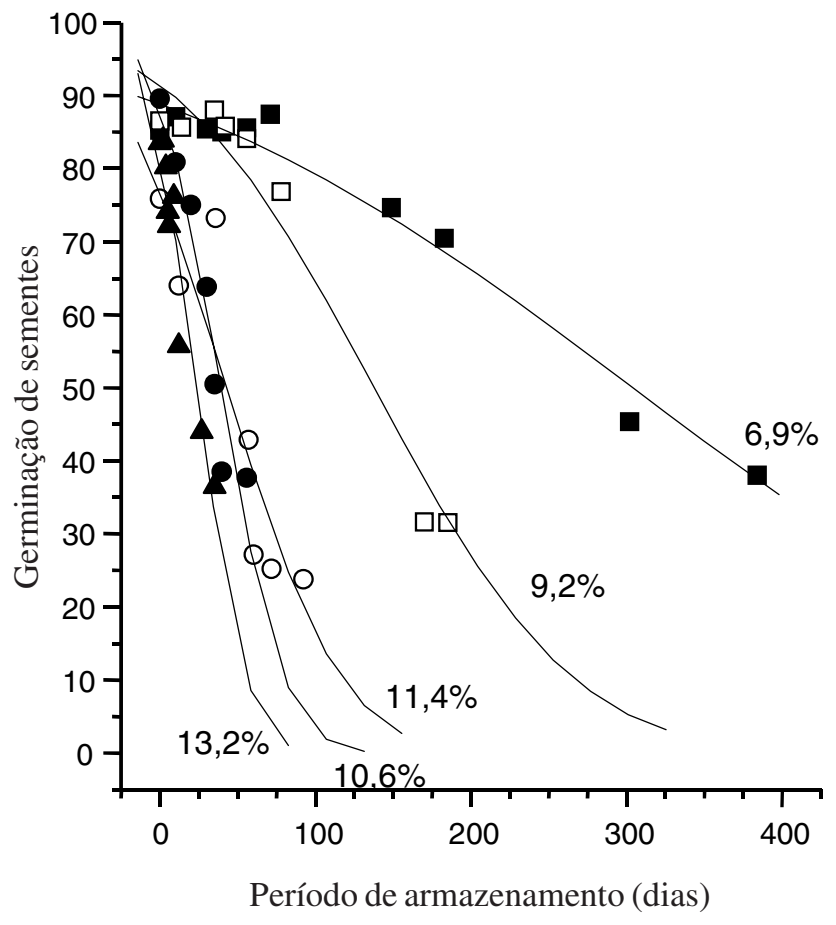

Figura 3. Curvas de sobrevivência de sementes de Dimorphandra mollis, armazenadas a $50{ }^{\circ} \mathrm{C}$ com graus de

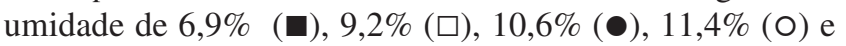
$13,2 \%(\Delta)$. Os símbolos e as linhas sólidas representam porcentagens de germinação e curvas de sobrevivência em probit, respectivamente.

Figure 3. Probit seed survival curves at $50{ }^{\circ} \mathrm{C}$ for Dimorphandra mollis with 6.9\% (ロ), 9.2\% ( $\square), 10.6 \%(\bullet)$, $11.4 \%(0)$ and $13.2 \%$ ( $)$ moisture content. Symbols and solid lines represent germination percentages and probit survival curves, respectively. em oito espécies e concluíram que o efeito relativo do potencial de água na semente foi o mesmo para todas elas e que, provavelmente, o fenômeno seja o mesmo em outras espécies.

Existe um consenso de que o grau de umidade é o fator mais importante na longevidade das sementes ortodoxas, como salientou Harrington (1963), ao estabelecer que a cada $1 \%$ de redução no grau de umidade ou de $5,6^{\circ} \mathrm{C}$ na temperatura, a longevidade dessas sementes dobra. Segundo Ellis \& Roberts (1980) e Ellis et al. (1982, 1986, 1990), para diversas espécies com sementes de comportamento ortodoxo há uma relação logarítmica negativa entre a longevidade das sementes e o grau de umidade, sendo que a relação com a temperatura é quadrática.

Trabalhando com duas espécies florestais, Tompsett (1986) verificou que aumentando o grau de umidade em sementes armazenadas em temperatura constante, ocorreu diminuição na longevidade prevista pela equação de Ellis \& Roberts (1980), nas faixas de grau de umidade de $3 \%$ a $19 \%$ para Ulmus carpinifolia e de $5 \%$ a $14 \%$ para Terminalia brassii, em todas as temperaturas usadas no experimento.

Constantes de viabilidade - Após a análise das variâncias residuais de cada curva de sobrevivência nas diferentes combinações de grau de umidade/temperatura, o melhor ajuste para a equação de viabilidade foi alcançado com a remoção dos resultados referentes ao menor grau de umidade $(1,6 \%)$ a $65^{\circ} \mathrm{C}$.

As constantes obtidas para a espécie definem a equação a $40{ }^{\circ} \mathrm{C}, 50{ }^{\circ} \mathrm{C}$ e $65^{\circ} \mathrm{C}$, a saber: $K=7,426$; 5,$955 ; 2,317$ e $C_{W}=4,881 ; 4,097 ; 1,893$, respectivamente. Não foi detectado o limite inferior para a aplicação da equação de viabilidade, porque os valores de grau de umidade muito baixos (em equilíbrio com UR menor que 20\%) não foram incluídos neste estudo (tabela 2)

As constantes $K_{E} \mathrm{e} \mathrm{C}_{W}$, estimadas neste trabalho para D. mollis foram 6,282 e 3,838, respectivamente, enquanto que as constantes que refletem a sensibilidade da longevidade à temperatura $\left(C_{H}\right.$ e $\left.C_{Q}\right)$ foram 0,05405 e 0,001316. Essas constantes podem ser empregadas para estimar a longevidade das sementes durante o armazenamento e permitem um prognóstico seguro para qualquer lote homogêneo de sementes, dentro de uma ampla faixa de condições de armazenamento, como foi observado por Tompsett (1989).

Assim, a equação de viabilidade para estimar a longevidade de sementes de $D$. mollis é:

$\mathrm{v}=K i-\mathrm{p} / 10^{6,282-3,838 \cdot \operatorname{logm}-0,05405 t-0,001316 t 2}$

A figura 5 mostra a relação logarítmica entre o grau de umidade das sementes e o desvio padrão da 
freqüência de distribuição das sementes mortas no tempo (sigma), a $40{ }^{\circ} \mathrm{C}, 50{ }^{\circ} \mathrm{C}$ e $65{ }^{\circ} \mathrm{C}$. Não houve interação significativa do logaritmo do grau de umidade das sementes e a temperatura de armazenamento $(F=1,29$, não significativo a $p<0,01)$.

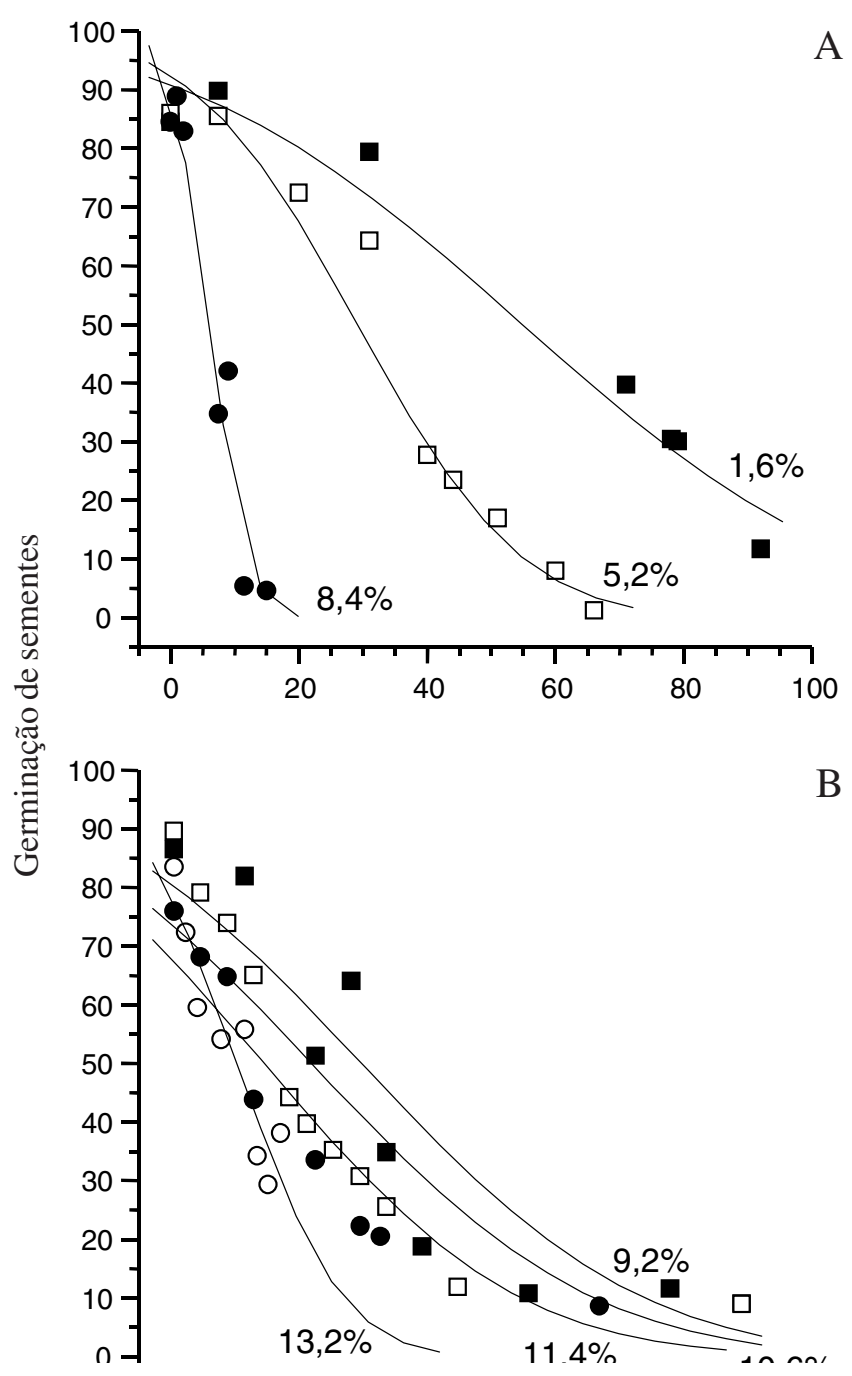

Período de armazenamento (dias)

Figura 4. Curvas de sobrevivência de sementes de Dimorphandra mollis, armazenadas a $65{ }^{\circ} \mathrm{C}$ com graus de umidade de $1,6 \%(\square), 5,2 \%(\square), 8,4 \%$ (•) (A) e 9,2\% (ロ), $10,6 \%$ (口), $11,4 \%$ (•) e 13,2\% (O) (B). Os símbolos e as linhas sólidas representam porcentagens de germinação e curvas de sobrevivência em probit, respectivamente.

Figure 4. Probit seed survival curves at $65{ }^{\circ} \mathrm{C}$ for Dimorphandra mollis with $1.6 \%(\square), 5.2 \%(\square), 8.4 \%(\bullet)(A)$ and $9.2 \%(\square), 10.6 \%(\square), 11.4 \%(\bullet)$ and $13.2 \%(\mathrm{O})(\mathrm{B})$ moisture content. Symbols and solid lines represent germination percentages and probit survival curves, respectively.
Medeiros (1996), utilizando os valores estimados de $C_{W}=3,76$ e $K_{E}=7,55$ na equação de viabilidade, com a temperatura de $-20{ }^{\circ} \mathrm{C}$ e o grau de umidade das sementes em equilíbrio higroscópico a $15^{\circ} \mathrm{Ce} 15 \%$ UR, verificou que o período previsto para a viabilidade das sementes de Astronium urundeuva (Fr. All.) Engl. cair de um probit seria de 1.167 anos.

Aplicando-se as constantes de viabilidade calculadas na equação de viabilidade de Ellis \& Roberts (1980) a $-20^{\circ} \mathrm{C}$ e grau de umidade de $2,9 \%$ (base úmida), verifica-se que serão necessários 316 anos para que as sementes de $D$. mollis apresentem redução de um probit em sua germinação.

Finalmente, foi observada uma relação inversa entre o grau de umidade e a longevidade das sementes de Dimorphandra mollis; além disso essas sementes

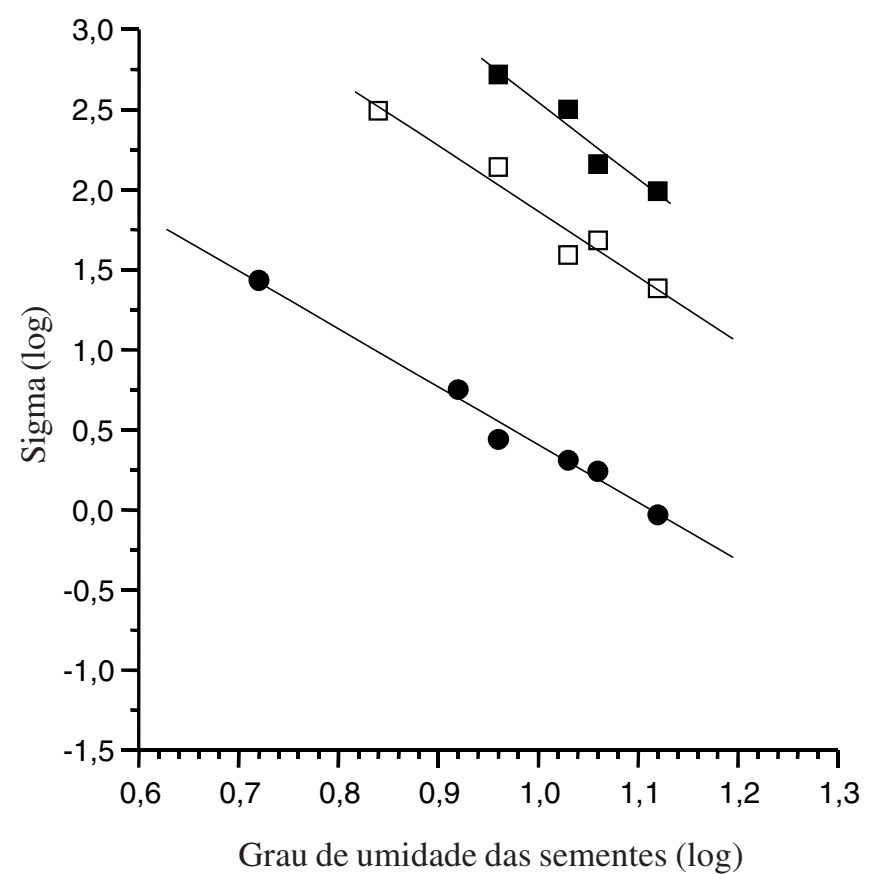

Figura 5. Relação logarítmica entre o grau de umidade (\%) e o desvio padrão da distribuição de freqüência das sementes mortas no tempo (sigma) para sementes de Dimorphandra mollis armazenadas a $40^{\circ} \mathrm{C}(\mathbf{\square}, \mathrm{Y}=7,33904-4,79284 \mathrm{X} ; \mathrm{R}=$ 0,96884), $50{ }^{\circ} \mathrm{C}(\square, \mathrm{Y}=5,95402-4,08984 \mathrm{X} ; \mathrm{R}=0,97493) \mathrm{e} 65^{\circ} \mathrm{C}$ (•, Y=4,01954 - 3,61054X; $\mathrm{R}=0,99309)$. As linhas sólidas indicam inclinações com um valor comum de origem.

Figure 5. Logarithm relationship between seed mc (f.wt) and the standard deviation of the frequency distribution of seed deaths in time (sigma) for Dimorphandra mollis, in hermetic storage at $(\square, Y=7.33904-4.79284 X ; R=0.96884), 50{ }^{\circ} \mathrm{C}(\square$, $\mathrm{Y}=5.95402-4.08984 \mathrm{X} ; \mathrm{R}=0.97493)$ and $65^{\circ} \mathrm{C}(\bullet, \mathrm{Y}=4.01954$ - 3.61054X; $R=0.99309)$. Solid lines stand for slopes which are constrained to one common value. 
mostraram comportamento ortodoxo em relação ao armazenamento, podendo portanto ser armazenadas com segurança, por longos períodos, em bancos de germoplasma.

Agradecimentos - Ao CNPq, pela bolsa de Doutorado de Maria Madalena Ferreira Chaves e ao Centro de Tecnologia em Embalagem (Cetea/Ital, Campinas) pela detecção da atividade de água e armazenamento hermético das sementes.

\section{Referências bibliográficas}

BAKER, C.J. \& NELDER, J.A. 1978. The GLIM system. Release 3. Numerical Algorithms Group, Oxford.

BEWLEY, J.D. \& BLACK, M. 1994. Seeds: physiology of development and germination. Plenum Press, New York.

BRASIL. 1992. Regras para análise de sementes. Secretaria Nacional de Defesa Agropecuária, Ministério da Agricultura e Reforma Agrária, Brasília.

DICKIE, J.B. \& SMITH, R.D. 1995. Observations on the survival of seeds of Agathis sp. stored at low moisture contents and temperature. Seed Science Research 5:5-14.

ELLIS, R.H. 1984. The meaning of viability. In Seed management techniques for genebanks. (J.B. Dickie, S.H. Linington \& J.T. Williams, eds.). International Board for Plant Genetic Resources, Rome, p.146-178.

ELLIS, R.H., HONG, T.D. \& ROBERTS, E.H. 1986. Logarithmic relationship between moisture content and longevity in sesame seeds. Annals of Botany 57:499-503.

ELLIS, R.H., HONG, T.D. \& ROBERTS, E.H. 1988. A lowmoisture-content limit to logarithmic relations between seed moisture content and longevity. Annals of Botany 61:405-408.

ELLIS, R.H., HONG, T.D., ROBERTS, E.H. \& TAO, K.L. 1990. Low moisture content limits to relations between seed longevity and moisture. Annals of Botany 65:493-504.

ELLIS, R.H., OSEI-BONSU, K. \& ROBERTS, E.H. 1982. The influence of genotype, temperature and moisture on seed longevity in chickpea, cowpea and soybean. Annals of Botany 50:69-82.

ELLIS, R.H. \& ROBERTS, E.H. 1980. Improved equations for the prediction of seed longevity. Annals of Botany 45:13-30.
HALL, C.W. 1980. Drying and storage of agricultural crops. The AVI Publishing, Westport.

HARRINGTON, J.F. 1963. Practical advice and instructions on seed storage. Proceedings of the International Seed Testing Association 28:989-994.

HONG, T.D. \& ELLIS, R.H. 1996. A protocol to determine seed storage behaviour. Technical Bulletin. International Plant Genetic Resources Institute, Rome.

LABOURIAU, L.G. 1983. A germinação das sementes. OEA, Washington.

MEDEIROS, A.C.S. 1996. Comportamento fisiológico, conservação de germoplasma a longo prazo e previsão de longevidade de sementes de aroeira (Astronium urundeuva (Fr. All.) Engl.). Tese de doutorado, Universidade Estadual Paulista "Júlio de Mesquita Filho", Jaboticabal.

SILVA, M.F. 1986. Dimorphandra (Caesalpiniaceae). Flora Neotropica. The York Botanical Garden, New York, p.1-26.

TOMASSINI, E. \& MORS, W.B. 1966. Dimorphandra mollis Benth. e D. gardneriana Tull., novas e excepcionais fontes de rutina. Anais da Academia Brasileira de Ciências 38:321-323.

TOMPSETT, P.B. 1986. The effect of temperature and moisture content on the longevity of seed of Ulmus carpinifolia and Terminalia brassii. Annals of Botany 57:875-883.

TOMPSETT, P.B. 1989. Predicting the storage life of orthodox tropical forest tree seeds. In Tropical tree seed research. (J.W. Turnbull, ed.). Aciar Proceedings 28:93-98.

USBERTI, R. \& GOMES, R.B.R. 1998. Seed viability constants for groundnut. Annals of Botany 82:691-694.

VALENTINI, S.R.T. 1992. Efeito da secagem de sementes de peroba-rosa (Aspidosperma polyneuron M. Arg.). Tese de mestrado, Universidade Estadual de Campinas, Campinas.

VERTUCCI, C.W. \& LEOPOLD, A.C. 1987. Water binding in legume seeds. Plant Physiology 85:224-231.

XIARONG, H., YUNLAN, Z., CHENGLIAN, H., MEI, T. \& SHUPING, C. 1998. A comparison of methods for drying seeds: vacuum freeze-drier versus silica gel. Seed Science Research 8 (supplement 1):29-33. 